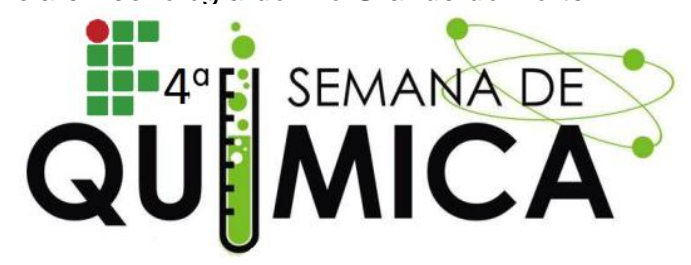

\title{
ENSINO DE QUÍMICA: APRENDIZAGEM SIGNIFICATIVA POR MEIO DO KAHOOT EM PSICOLOGIA DA EDUCAÇÃO
}

*AZEVEDO, L.D.(IFRN); COSTA J.K.L.(IFRN); SILVA, S.H.A.(IFRN) BEZERRA, M.C.(UFRN)

Palavras Chave: Aprendizagem significativa; Kahoot; psicologia da educação.

\section{INTRODUÇÃO}

$O$ ensino aprendizagem com alunos da licenciatura de Química na disciplina de psicologia é um grande desafio. Devido o cenário educacional mundial, a internet e outras tecnologias digitais está se ampliando envolvendo de forma combinada o desenvolvimento de aprendizagens significativas de Ausubel (1982). Nesse contexto, este trabalho analisa as contribuições que o Kahoot trouxe para o ensino de química, que se apresenta como uma ferramenta em sala de aula gratuita na Web. O Kahoot é baseado em jogos com perguntas de múltiplas escolhas que permite aos educadores e estudantes investigar criar e oportunizar a interlocução de diversos saberes, a socialização e o desenvolvimento das interações pessoal, social, e cognitivo quando bem exploradas.

METODOLOGIA

Parte-se de uma abordagem qualitativa, que permite utilizar-se dos instrumentos de coleta de dados tais como: a observação participante e a aplicação de um questionário com 3 perguntas abertas para os alunos num total de 9. Neste sentido, estamos compartilhando uma prática de sala de aula, por meio de um relato de experiência que foi desenvolvido com alunos do curso de licenciatura em química em Currais Novos, na disciplina: Psicologia da educação. Esta experiência foi desenvolvida pela Professora da referida disciplina, no intuito de sair do ensino convencional e adotando uma nova forma de aplicar uma avaliação, e obter maior interesse do aluno. Os dados foram analisados de forma compreensiva por meio das respostas e apresentadas no formato de um gráfico.

RESULTADOS E DISCUSSÕES

Com base nas análises feitas constamos os seguintes resultados: que todos os participantes se mostraram bastante entusiasmados, inclusive afirmando que, anteriormente os questionários eram feitos de modo tradicional e que, desta forma, conseguiram interagir, assimilar e compreender mais o conteúdo, tornando a aprendizagem mais significativa e contextualizada.

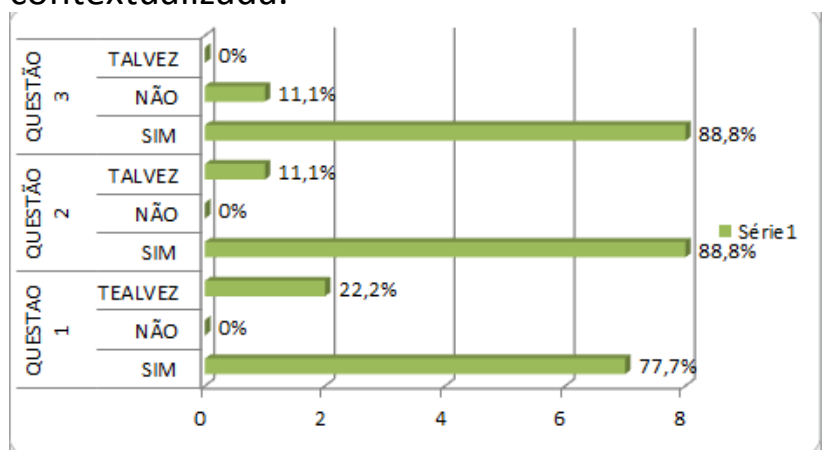

Figura 2 - :Q1 Eficácia educativa; Q2: Importância como ensino aprendizagem; Q3: Absorção do conteúdo.

CONCLUSÃO

Pode-se concluir que, a utilização da ferramenta Kahoot em sala de aula é de significativa eficiência como ferramenta pedagógica para o ensino de química, pois constatou-se que, no desenvolvimento do processo os alunos mostraram-se envolvidos motivados com uma participação efetiva e significativa com a proposta que foi utilizada dentro de sala de aula.

REFERÊNCIAS

Moreira, M.A. e Buchweitz, B. (1993). Novas estratégias de ensino e aprendizagem. Lisboa: Plátano Edições Técnicas.

Moreira, M.A. e Masini, E.A.F. (1982). Aprendizagem significativa: a teoria de David Ausubel. São Paulo: Editora Moraes.

Silva, B; Cordeiro, R.M.; Kiill, B.K. Jogos didático investigativo: Uma ferramenta para o ensino de Química Inorganica. Revista Química Nova na Escola. Vol. 37, № 1 p 27-34 São Paulo 